Atmos. Chem. Phys., 10, 2377-2391, 2010

www.atmos-chem-phys.net/10/2377/2010/

(C) Author(s) 2010. This work is distributed under

the Creative Commons Attribution 3.0 License.

\title{
On the transitions in marine boundary layer cloudiness
}

\author{
I. Sandu ${ }^{1}$, B. Stevens ${ }^{1,2}$, and R. Pincus ${ }^{3}$ \\ ${ }^{1}$ Max Planck Institute for Meteorology, Hamburg, Germany \\ ${ }^{2}$ University of California at Los Angeles, Los Angeles, California, USA \\ ${ }^{3}$ University of Colorado/NOAA Earth System Research Lab, Boulder, Colorado, USA
}

Received: 2 October 2009 - Published in Atmos. Chem. Phys. Discuss.: 5 November 2009

Revised: 2 February 2010 - Accepted: 26 February 2010 - Published: 8 March 2010

\begin{abstract}
Satellite observations and meteorological reanalysis are used to examine the transition from unbroken sheets of stratocumulus to fields of scattered cumulus, and the processes controlling them, in four subtropical oceans. A Lagrangian analysis suggests that both the transition, defined as the temporal evolution in cloudiness, and the processes driving the transition, are quite similar among the subtropical oceans. The increase in sea surface temperature and the associated decrease in lower tropospheric stability appear to play a far more important role in cloud evolution than other factors including changes in large scale divergence and upper tropospheric humidity. During the summer months, the transitions in marine boundary layer cloudiness appear so systematically that their characteristics obtained by documenting the flow of thousands of individual air masses are well reproduced by the mean (or climatological) fields of the different data sets. This highlights interesting opportunities for future observational and modeling studies of these transitions.
\end{abstract}

\section{Introduction}

A striking feature of the global cloud climatology is the transition from unbroken sheets of stratocumulus to fields of scattered cumulus that occurs as boundary-layer air masses advect equatorward in the trades (Von Ficker, 1936; McDonald, 1938; Neiburger et al., 1961; Malkus and Riehl, 1964; Klein and Hartmann, 1993). In the eastern basins of the subtropical oceans, the regions adjacent to the continental coasts

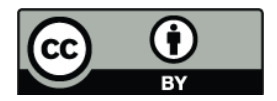

Correspondence to: I. Sandu (irina.sandu@zmaw.de) are frequently covered by extensive sheets of stratocumulus. These stratocumulus sheets form over relatively cold seasurface temperatures (SSTs), in shallow and generally wellmixed boundary layers capped by a strong temperature inversion. As the air masses advect equatorward over warmer SSTs and towards lower mean large-scale subsidence, the inversion generally weakens and rises and the stratocumulus decks break-up. Ultimately, the stratocumulus is replaced by scattered, predominantly shallow cumulus. The shift, or transition in cloud regimes has a profound effect on the local albedo, and begs explanation, particularly by those interested in understanding the factors controlling the planetary albedo as a whole.

Early studies of the stratocumulus to cumulus transition followed the equatorward advection of a cloudy air column and documented its evolution either in situ (Albrecht et al., 1995; Bretherton and Pincus, 1995; De Roode and Duynkerke, 1997), or from satellite data and operational weather analysis (Pincus et al., 1997). Such a Lagrangian perspective on the cloud evolution naturally accounts for both the time-varying boundary conditions experienced by the air mass during its equatorward advection and the timescale on which the boundary layer clouds adjust to such environmental changes (Schubert et al., 1979; Klein and Norris, 1995; Pincus et al., 1997). The structure of the transition documented by these observational studies was further explored with mixed-layer models and two-dimensional fine-scale numerical simulations (Bretherton, 1992; Bretherton and Wyant, 1997; Bretherton et al., 1999; Krueger et al., 1995; Wyant et al., 1997; Stevens, 2000). This work led to the development of a simple conceptual model of the transition. According to this model, the cloud breakup is fundamentally driven by increasing SSTs. Convective activity

Published by Copernicus Publications on behalf of the European Geosciences Union. 
driven by the surface latent heat fluxes increases as the air advects over warmer waters. The strengthening of convectively driven turbulence enhances the entrainment of warm and dry free-tropospheric air at cloud top, which leads to a differentiation (stabilization) of the cloud with respect to the subcloud layer. This differentiation inhibits the transport of moisture towards the cloud layer which allows the subcloud layer to become conditionally unstable relative to the cloud layer. Cumulus clouds thus develop to recouple the cloud and subcloud layers, but with a fundamentally different dynamics than that of the stratocumulus they replace. Meanwhile, the stratocumulus gradually thins and evaporates due to increased entrainment at cloud top and reduced moisture supply from the surface. Finally, it dissipates into thin and broken patches, penetrated from below by cumulus clouds.

Ideas about the transitions in marine boundary layer cloudiness have been so far based on a relatively small number of case studies drawn exclusively from the Northern Hemisphere. But the stratocumulus to cumulus transition occurs in other places, particularly in the Southern Hemisphere. Here we seek to understand the extent to which the transition is similar in the different regions in which it occurs and thus encapsulates some generic underlying process that one could hope to explain. We also seek to understand the relationship between the character of the transition along individual trajectories, and the climatological transition evident in seasonally averaged maps of cloudiness.

To answer these questions we compute a large number of Lagrangian trajectories of air parcels in the eastern subtropical oceans. The evolution of the cloud and of its environment along each of these individual trajectories is then evaluated using observational data, including satellite measurements and meteorological reanalysis, all of which have been refined in recent years. From these observations we build a Lagrangian view of the transitions in marine boundary layer cloudiness, which we compare to the Eulerian view available from climatology.

Section 2 provides a description of our methodology and of the data sets employed for analyzing the downstream evolution of the air parcels. Section 3 examines whether the transition in cloudiness and its associated meteorological context differ from one ocean basin to another. The factors modulating these transitions are discussed in Sect. 4. Section 5 investigates the differences between our Lagrangian view of the transition in marine boundary layer cloudiness and the classical Eulerian view of this transition supplied by cloud climatologies, and Sect. 6 summarizes our major findings.

\section{Lagrangian analysis of the air masses flow in the eastern subtropical oceans}

To examine the transitions in marine boundary layer cloudiness, we compute the trajectories of individual air parcels, using the wind fields provided by reanalysis of past obser- vations. Then, we extract the cloud and the meteorological properties of the air parcel at different locations along these trajectories from various data sets. This Lagrangian technique of analyzing the air flow was previously used by Pincus et al. (1997) to examine the transition from stratocumulus to cumulus observed over the northeast Pacific in several dozen cases, and by Mauger and Norris $(2007,2010)$ to investigate the impact of meteorological history on the subtropical cloudiness in the northeast Atlantic.

Here we apply this technique systematically in four of the eastern subtropical oceans where such transitions occur, i.e. northeast, and respectively southeast, Atlantic and $\mathrm{Pa}-$ cific (NEA, SEA, NEP, SEP hereafter). Although the eastern boundary current region west of Australia was not included in our analysis, the cloud regimes there are similar to those analyzed. Given the similarity in the dynamics across the regions we chose to analyze we do not expect that the inclusion of this regime in our analysis would affect our conclusions. Our analysis covers a six month period centered around the month of maximum cloud fraction in each basin (i.e. May to October for the Northern Hemisphere and July to December for the southern one), and spans the period 2002-2007.

\subsection{Computing trajectories}

We compute daily 3-dimensional forward trajectories in each of the four subtropical oceans using the Hybrid SingleParticle Lagrangian Integrated Trajectory Model (HYSPLIT) (http://ready.arl.noaa.gov/HYSPLIT.php) driven by gridded meteorological fields from the interim reanalysis of the $\mathrm{Eu}-$ ropean Centre for Medium-Range Weather Forecasts - the ERA-INTERIM (Simmons et al., 2008). Each trajectory begins at 11:00 local time (LT) and lasts for six days. This starting time was chosen to be close to the Equator crossing time of the Terra Earth Observing System platform, which is approximately 10:30 LT. The Moderate Resolution Imaging Spectroradiometer (MODIS) onboard Terra can thus be used to estimate the cloud amount at the beginning of the trajectories.

We initialize trajectories at nine equally spaced points within each of four $10^{\circ} \times 10^{\circ}$ boxes where stratocumulus decks occur most frequently (black squares in Fig. 1, after Table 1 of Klein and Hartmann, 1993), which yields approximately 10000 trajectories for each region (Table 1). To identify the provenance of the analyzed air masses, we also perform daily backward trajectories that start from the same locations, at the same time and that have the same duration as the forward trajectories.

Both the forward and the backward trajectories are initialized within the boundary layer, at a height of $200 \mathrm{~m}$ above sea level. This level was chosen to be well within the boundary layer, yet avoid undue influence from the surface. The probability distribution of the air parcels altitude at the end of the forward trajectories indicates that most of the analyzed air parcels are still in the boundary layer after six 
Table 1. Total number of trajectories, percentage going over warmer waters ( $\mathrm{S}$ or SW in the Northern Hemisphere, N or NW in the Southern Hemisphere), range of the initial MODIS Terra liquid cloud fraction for the selected 3000 trajectories.

\begin{tabular}{cccc}
\hline Zone & $\begin{array}{c}\text { Total number } \\
\text { of trajectories }\end{array}$ & $\begin{array}{c}\text { Percentage going } \\
\text { over warmer waters }(\%)\end{array}$ & $\begin{array}{c}\text { Range of the initial cloud fraction } \\
\text { for the selected 3000 trajectories }\end{array}$ \\
\hline NEA & 9936 & 73. & {$[0.386-1]$} \\
SEA & 9882 & 53.71 & {$[0.886-1]$} \\
NEP & 9936 & 85.7 & {$[0.915-1]$} \\
SEP & 9882 & 72.25 & {$[0.9-1]$} \\
\hline
\end{tabular}
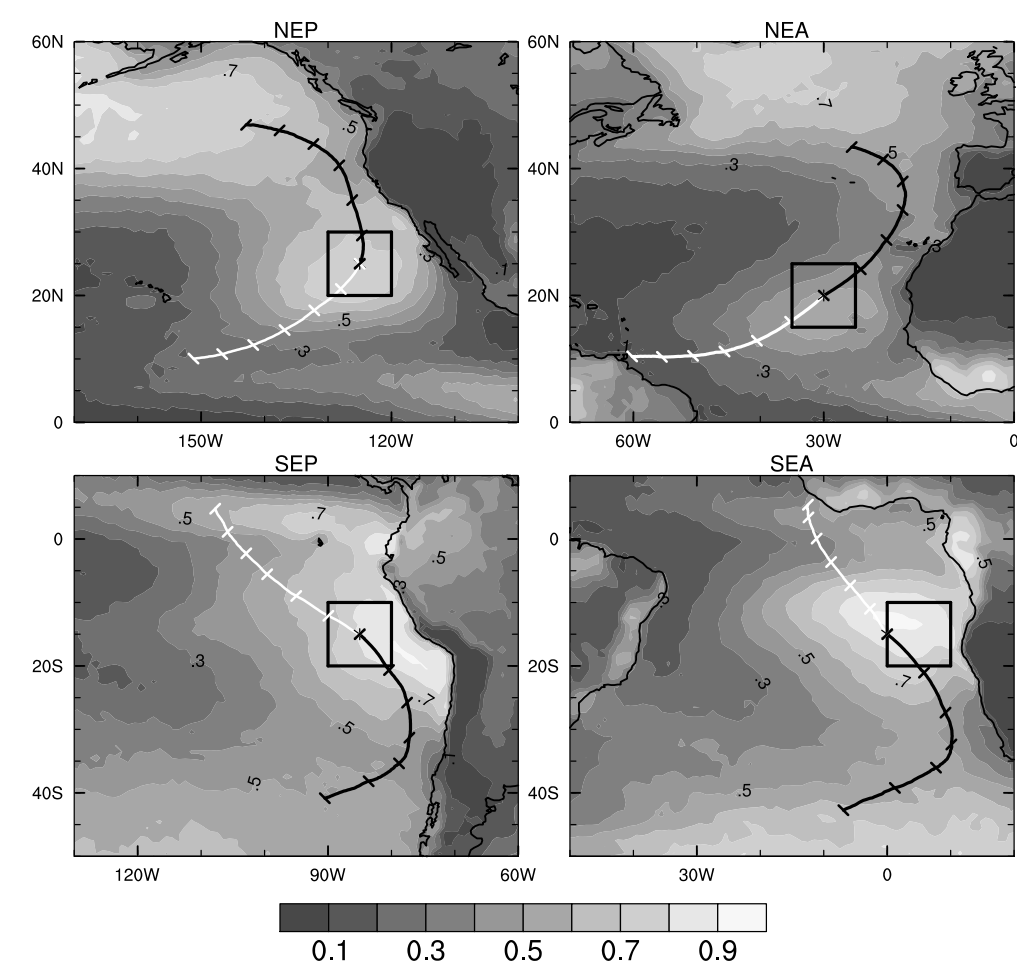

Fig. 1. Average of MODIS Terra morning liquid cloud fraction over the third day of the selected trajectories, and medians of the forward (white lines) and the backward (black lines) sets of trajectories analyzed in each zone. The tickmarks on the median trajectories indicate the position of the air parcel every $24 \mathrm{~h}$. The squares indicate the stratocumulus regions studied by Klein and Hartmann (1993).

days. Similarly, for the backward trajectories, most of the air parcels come from the boundary layer (not shown).

\subsection{Characterizing the clouds and their environment}

To document the evolution of the air mass properties along each of the forward trajectories, we use observations from the Moderate Resolution Imaging Spectroradiometer (MODIS); the Advanced Microwave Scanning Radiometer for Earth Observing System (AMSR-E) and from the Global Precipitation Climatology Project (GPCP). Additionally we evaluate the meteorological state along the trajectories using data provided by the ERA-INTERIM.
We estimate cloud and environmental properties hourly (or whenever data is available) along the trajectory as the average of all data from grid boxes within $1^{\circ}$ of the air parcel location at the observation/reanalysis time. Because the various data sets have slightly different spatial resolution, this will represent the average over a somewhat slightly bigger or smaller area depending on the data set's resolution. The following paragraphs indicate which data sets are used to characterize the Lagrangian evolution of the clouds and of their environment. 


\subsubsection{Environmental properties}

For the environmental properties, we use the gridded meteorological fields of ERA-INTERIM reanalysis, which have a spatial resolution of $1.5^{\circ} \times 1.5^{\circ}$ and a temporal resolution of $6 \mathrm{~h}$. From this data set, we use the 3-dimensional fields of wind, temperature and relative humidity to compute the trajectories of air parcels with HYSPLIT. Additionally, along each trajectory we extract the SST, the large scale divergence and the profiles of specific humidity and temperature. The values of the large scale divergence represent the average divergence within the boundary layer (i.e. the average of the ERA-INTERIM divergence profile from $1000 \mathrm{hPa}$ to $900 \mathrm{hPa}$ ).

\subsubsection{Cloud and aerosol properties}

We describe the cloud fraction, the cloud optical thickness and the aerosol optical depth along the trajectories from the Collection 5 of the MODIS Level-3 products (Platnick et al., 2003; King et al., 2003), which contain global gridded statistics at a resolution of $1^{\circ} \times 1^{\circ}$. We use data from both the Terra and Aqua platforms, so that two measurements per day are available, shortly after their equatorial crossing times of 10:30 and 13:30 respectively, which differ from local times only by a few minutes to tens of minutes depending on the latitude. Cloud and aerosol products are available only during daylight. We use the Cloud Fraction Liquid product, which describes the fraction in pixels in which cloud properties were successfully retrieved. This estimate of cloud fraction is smaller than estimates based solely on cloud detection, sometimes by tens of percent, but is consistent with MODIS estimates of optical thickness and liquid water path. Details about the Cloud Fraction Liquid product, its use in our analysis, and the uncertainties in measuring cloud fraction are given in Appendix A.

\subsubsection{Atmospheric vapor content and precipitation}

We document the total vapor content of the atmosphere from the AMSR-E data set. AMSR-E is flying onboard Aqua, so that two measurements per day are available, at about 01:30 and 13:30 local time. This data set is provided on a $0.25^{\circ} \times$ $0.25^{\circ}$ grid.

We also describe the evolution of the surface precipitation rate from the data set provided by the GPCP, which contains daily averages of the precipitation rate at the surface on a $1^{\circ} \times 1^{\circ}$ global grid.

\subsection{Conditional sampling}

We examine the characteristics of the transition in cloudiness and of its associated environmental context in each of the four subtropical regions, based on the trajectories that are the most likely to experience such a transition. To determine these trajectories for each region, we select those corresponding to the air parcels advected over warmer waters (south or southwestward in Northern Hemisphere, north or northwestward in the Southern Hemisphere). From those trajectories, we then choose the set of 3000 trajectories that have the highest initial cloud fraction (which roughly corresponds to $30 \%$ of the total number of trajectories). We then explore the characteristics of the distribution of cloud amount and of environmental properties over these 3000 trajectories.

\section{Mean structure of the transition in cloudiness}

In this section we examine the collection of Lagrangian trajectories to investigate whether the transitions in cloud fraction share a similar underlying dynamics.

\subsection{The transition in cloud fraction}

\subsubsection{Spatial structure}

Our analysis includes only about a third of all possible scenes, but the cloud statistics composited over the days (Fig. 1) we sample are quite similar to simple seasonal averages. In all four oceans the subtropical cloud cover is maximum within (or nearby) the stratocumulus regions of Klein and Hartmann (1993) and it decreases gradually equatorwards. The cloud fraction is higher in the southern oceans, on average, than in the northern ones, with cloud fractions being markedly lower in the NEA (Klein and Hartmann, 1993). This means that trajectories in the Southern Hemisphere start at higher cloud fractions than do those north of the equator (Table 1 and Fig. 1).

The same is true for the broad air masses circulation within the boundary layer, as the trajectories more or less follow the geostrophic wind, with cross-isobaric flow consistent with Ekman effects. As showed by the median backward and forward boundary layer trajectories in Fig. 1 (full lines), the trajectories predominantly follow anticyclonic paths, starting in the storm track regions in midlatitudes, passing through a maximum of cloudiness (i.e. the stratocumulus regions) and ending up in the trade winds regions.

Although the equatorward flow of the analyzed air masses looks overall quite similar in the four regions, there are some differences, most notably between the trajectories in the two hemispheres. The air flow has a cross-equatorial component in the Southern Hemisphere. The southern trajectories seem thus to pass through a minimum of cloudiness when they cross the equator, and they become more meridional afterwards. In the SEA roughly half the trajectories end up on the African coast, which means that they do not enter in the composites (Table 1). Consequently, the forward trajectories selected for this region start predominantly from the western half of the starting box, while in the other regions they are equally likely to start from any of the nine starting points. 
Figure 1 highlights the similarities and differences between the sets of trajectories analyzed in the four subtropical oceans and gives an image of the average cloud fraction typical for the situations analyzed within each of these regions. To gain more quantitative information about these transitions in marine boundary layer cloudiness, in the next section we explore the composite temporal evolution of the cloud fraction along the trajectories.

\subsubsection{Temporal evolution}

The time evolution of the cloud-fraction distribution for the 3000 trajectories analyzed in each of the four subtropical oceans is illustrated in Fig. 2. Because the trajectories in the NEA start with cloud fractions lower than those in the other regions (Table 1 and Fig. 1) we adjust the initial time in this region so that the median trajectory starts with the same value as the one from the zone with the highest cloud fraction (SEA) (for Figs. 2 and 3). This facilitates the comparison between the different regions.

From this Lagrangian perspective, the transition in cloud fraction looks similar in all four subtropical oceans. As we show in Appendix A this result does not depend on our choice of the cloud fraction product. In each case, the stratocumulus deck breaks-up during the first three days of the trajectories (as suggested by the decrease of the median cloud fraction on day 3 to less than half of its initial value, Fig. 2, lower panel). The cloud break-up is not accompanied by significant changes in the cloud liquid water path or in the cloud top temperature, although as discussed in Appendix B the remote sensing of these quantities is problematic, which makes it difficult to draw conclusions.

After the third day, the air parcels enter a shallow cumulus regime and the cloud fraction undergoes more subtle variations. Our identification of the first three days as the period of the transition is consistent with increased variability in cloud fraction during this period (Fig. 2, upper panel). Such variability is precisely what we would expect if the cloud fraction is changing significantly during this period, as slight variations in the start of the transition would translate into increased variability.

\subsection{The environmental context}

Figure 2 shows that the transition in cloud fraction is independent of location; in this section we investigate whether the relationships between cloud fraction and the environment (and hence the mechanisms of the transition) are also consistent by examining the evolution of different environmental factors that might influence the transition in cloud fraction. These include SST, lower tropospheric stability (LTS, defined as the difference in potential temperature between $700 \mathrm{hPa}$ and the surface), large-scale divergence, column water and free-tropospheric humidity.

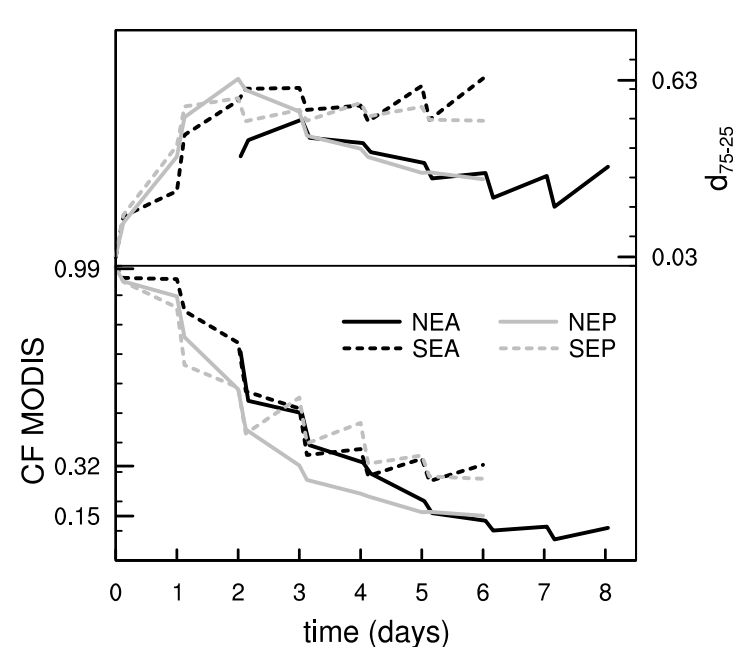

Fig. 2. MODIS liquid cloud fraction along the trajectories. The lower panel shows the evolution of the median and the upper panel illustrates the interquartile spread (i.e., the distance between the third and first quartile) of the distribution of the cloud fraction for the sets of trajectories analyzed in each of the four subtropical oceans. In the lower panel, the y-axis labels the values at the initial time, after 3 days and respectively at the end of the median trajectory for NEP; in the upper panel, it labels the minimum and the maximum values of the interquartile spread for the same region.

All these factors evolve similarly in the four subtropical oceans, albeit with different characteristic values in each region (Fig. 3). In all four regions the transition in cloud fraction is associated with strong changes in SST, hence with strong changes in LTS (Figs. 2, 3a and b). The transition is not, however, associated with significant changes in the large-scale divergence (at least on average, Fig. 3c, lower panel), or in the temperature above the boundary layer (not shown). Indeed, the median large-scale divergence decreases only after the third day, when the air parcels reach convective regions. The variability in the large-scale divergence among the trajectories also increases noticeably only after the cloud break-up (Fig. 3c, upper panel). As for the temperature above the boundary layer, it changes little during the six days and if anything, decreasing slightly equatorwards.

Atmospheric water vapor (Fig. 3d) tracks SST, and hence the transition in cloudiness, fairly well, since water vapor is closely linked to surface temperature. Although this is likely of secondary importance compared to the impact of the SST/LTS, it is possible that the gradual humidification of the free-troposphere (Fig. 3e) affects cloud evolution through its impacts on the cloud-top radiative cooling and drying of the cloud layer via mixing at its top. Indeed, the moistening of the free-troposphere enhances the downwelling longwave radiation, hence acts to decrease the radiative cooling at cloud top. Radiative transfer computations performed using 

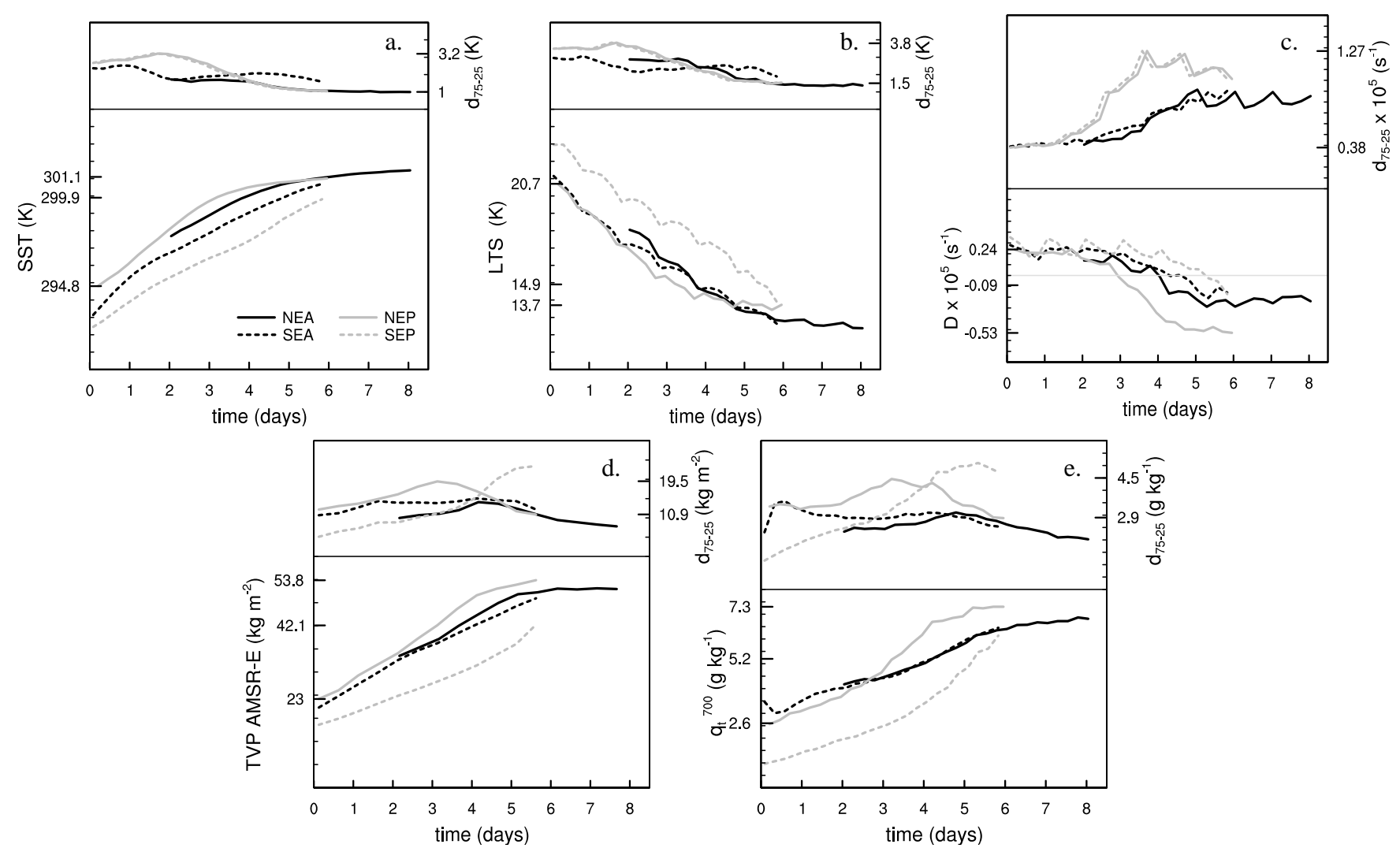

Fig. 3. Environmental factors along the trajectories: SST, lower tropospheric stability (LTS), large-scale divergence (D), AMSR-E total vapor path and ERA-INTERIM specific humidity at $700 \mathrm{hPa}$. Plotting conventions follow those in Fig. 2.

the initial median profiles of humidity and temperature for NEP show that an increase of the humidity of approximately $2 \mathrm{~g} / \mathrm{kg}$ from the inversion level $(1 \mathrm{~km})$ up to $3 \mathrm{~km}$, would decrease the cloud top radiative cooling by approximately $15 \%$. A decrease of the cloud top radiative cooling leads to less production of turbulence by cloud-top cooling, which all things being equal favors greater decoupling (Bretherton and Wyant, 1997; Stevens, 2000) and hence a thinning of the stratocumulus layer. If the moister free-troposphere extends to the top of the boundary layer, it would inhibit the entrainment drying of the cloud layer, which could favor more stratocumulus-like conditions, and thus counteract the radiative effect of elevated moisture. The overall effect of the humidification of the free-troposphere on cloud evolution is however difficult to quantify from observations alone. High resolution numerical simulations will be therefore used in future to examine the importance of such effects.

Our results corroborate the hypothesis that the SST increase, and the associated LTS decrease, are the main driving factors of the transition in cloud fraction (Bretherton, 1992). Because the large scale divergence does not decrease until the fourth day, when most of the decrease in cloud fraction has occurred, it appears that the change in large-scale subsi- dence along the trajectory plays a relatively minor role in the evolution of the cloud layer.

The inference that the changing subsidence rate plays a minor role in the stratocumulus-to-cumulus transition is perhaps not so surprising. Consider the median divergence rate during the first three days of the transitions (Fig. 3c). For a boundary layer of about $1000 \mathrm{~m}$, the subsidence velocity at its top would be of $2 \times 10^{-3} \mathrm{~m} / \mathrm{s}$. Imagine now that instead of remaining relatively constant, the divergence would linearly decrease to 0 during the third day. This would roughly imply an average change in the subsidence at the boundary layer top of $1 \times 10^{-3} \mathrm{~m} / \mathrm{s}$, and hence a total increase of the boundary layer depth of $86 \mathrm{~m}$ during the third day, that is less than $10 \%$ of its initial value. So even if the divergence would decrease from the second day on, this would appear to have a somewhat secondary impact on the evolution of the layer (at least for the median values of the divergence distribution).

Other factors not considered above may also play a role, for instance the atmospheric aerosol, or the development of precipitation (Wang et al., 1993). The observational record for these quantities is however more suspect. To the extent essential aspects of the climatology of aerosol optical depth, or precipitation, are well represented by the satellite record 
(e.g., as presented in Appendix B) neither changes in a fashion that can explain the observed changes in cloudiness.

\section{What differentiates fast and slow transitions?}

The temporal evolution of the environmental context during the equatorward air flow highlights the factors that affect the transition in cloud fraction. In this section we further explore the hypothesis that LTS is the dominant control on cloud evolution by comparing the differential evolution among subsets of trajectories. We divide the transitions in three categories, i.e. fast, intermediate and slow, and examine the differences between the fast and the slow transitions. The 3000 trajectories analyzed in each region are divided in the three categories on the basis of the mean cloud fraction over the first $72 \mathrm{~h}$. Thus, the subsets of fast and slow transitions correspond to the trajectories having the lowest, and respectively the highest, values for this 3-days average cloud fraction. We illustrate the results of this analysis only for the NEP (Figs. 4 and 5). However, consistent results are found for the other regions. The results are also consistent if different criterions are used for selecting the fast and the slow transitions, for e.g., the average cloud fraction over the first $48 \mathrm{~h}$, or the average cloud fraction during the second day.

Although the time evolution of the cloud fraction is by definition starkly different for the fast and the slow transitions, there appears to be little difference between the initial characteristics of the clouds, including median cloud fractions (Fig. 4) and optical thickness (not shown).

The environments in which the fast and the slow transitions occur are mainly distinguished by their values of SST and LTS (Fig. 5). The rate of change in SST or LTS along the trajectory, is however more or less constant between the two categories of transitions (Fig. 5a and b). This suggests that the pace of the transition depends on the absolute value of the SST/LTS rather than on its along-trajectory gradient. This finding is consistent with previous work linking LTS and the low-level cloud cover (Klein and Hartmann, 1993; Pincus et al., 1997; Mauger and Norris, 2010). The line of argument behind this idea is that a stronger inversion (hence a stronger LTS) limits the entrainment velocity at cloud top, which results in a reduced deepening and less drying of the boundary layer. The stronger LTS helps thus maintain a shallow and humid boundary layer driven predominantly by cloud top cooling, which is in turn conducive to an overcast and well-mixed layer.

If the SST/LTS dependency is removed by rescaling the time axis so that the trajectories experiencing fast and slow transitions start at the same median LTS, the spread in cloud fraction between the two subsets of trajectories is reduced by a factor of two (Fig. 6a and b). The remaining spread is mostly associated with the differences in free-tropospheric humidity, which is slightly higher for the slow transitions (Fig. 6c). This suggests that the humidity of the free tro-

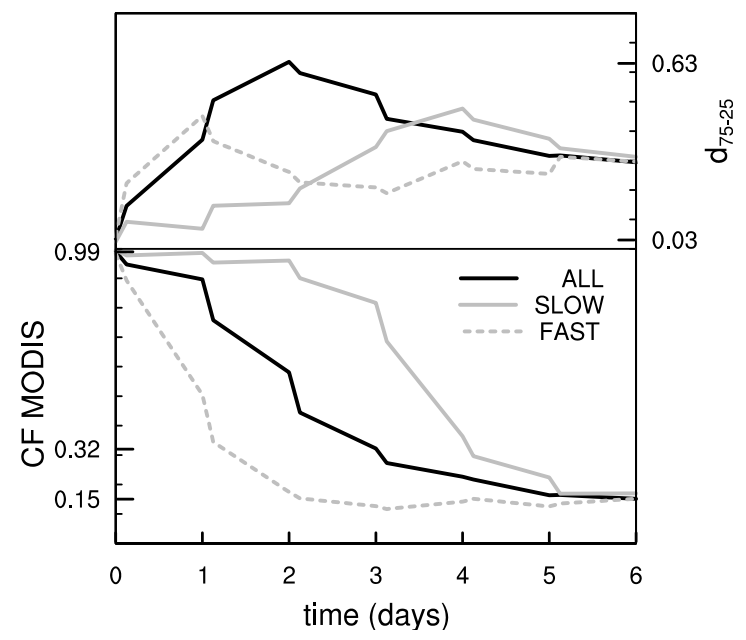

Fig. 4. Same as Fig. 2 for the set of trajectories analyzed for the NEP (black line), and for its subsets corresponding to the slowest (solid grey line) and respectively the fastest transitions (dashed grey line).

posphere (through the chain of events discussed previously) may be playing an important, albeit secondary, role in determining the evolution of the cloud layer.

\section{Composite versus climatological transition}

The transitions in boundary layer cloudiness and the factors controlling them appear consistent in the four subtropical ocean regions we have examined. Because the trade-winds, in which such transitions are embedded, are among the steadiest features of the general circulation (Riehl et al., 1951), one might expect the Eulerian view of the stratocumulus-tocumulus transition to be similar to what we find in our Lagrangian analysis. In this section we explore the similarity of these two views of the transition. To the extent we can show that they are similar one can take advantage of a great wealth of climatological data whose density is insufficient to support a lagrangian analysis, for instance measurements from instruments such as the CALIOP lidar on Cloud-Aerosol Lidar Infrared Pathfinder Satellite Observation (CALIPSO), the Multiangle Imaging SpectroRadiometer (MISR) on Terra, or the Cloud Profiling Radar on Cloudsat, each of which can provide qualitatively new information, but only over a narrow field of view.

We examine the differences between the composite transition build from our Lagrangian analysis and a climatological transition, built in an Eulerian frame. We limit ourselves to the three months with the highest cloud fraction in the stratocumulus region of each oceanic basin. That is June/July/August (JJA hereafter) for the northern oceans, and September/October/November (SON hereafter) for the southern ones (Klein and Hartmann, 1993). As it turns out, 

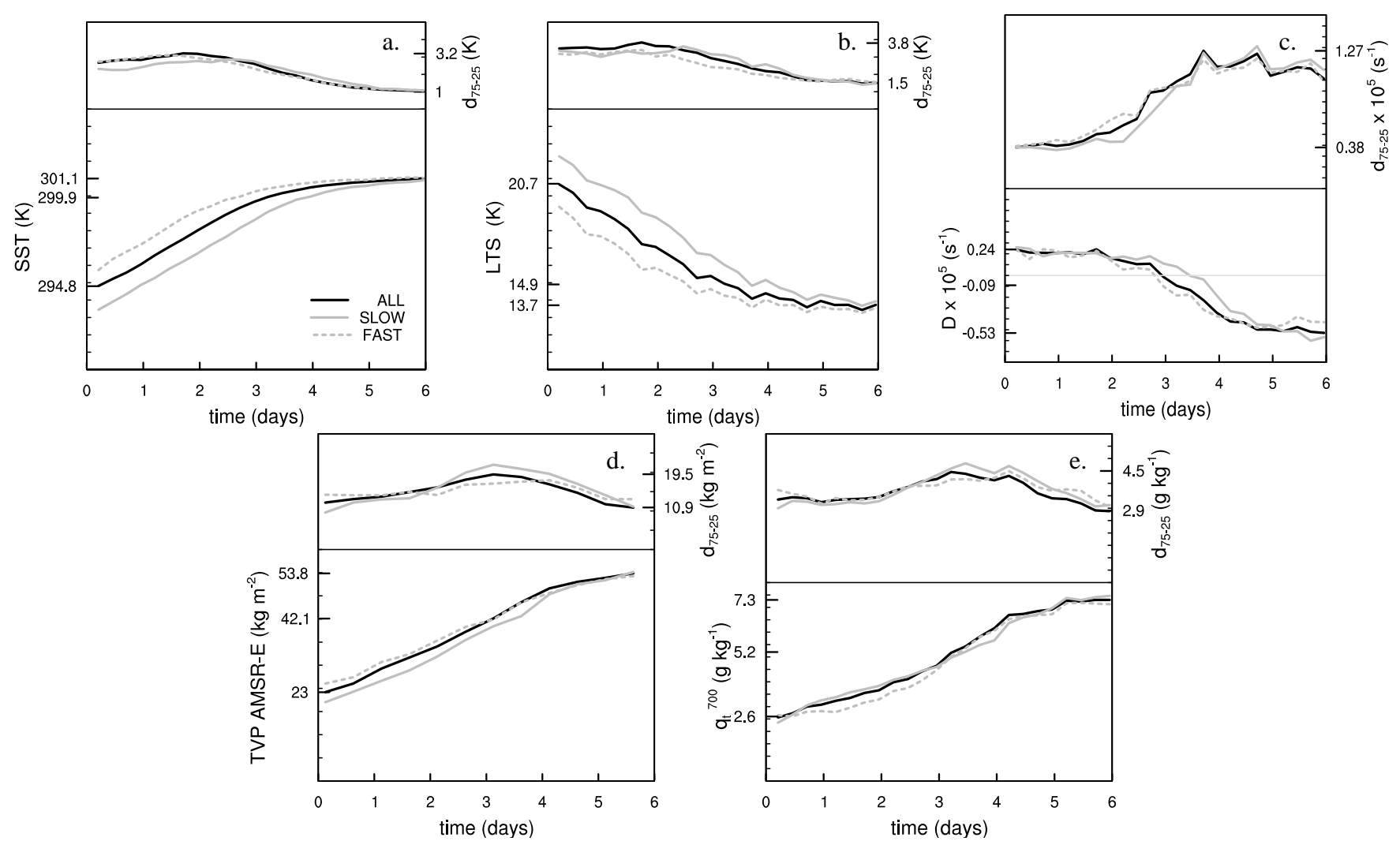

Fig. 5. Same as Fig. 3 for the set of trajectories analyzed for the NEP (black line), and for its subsets corresponding to the slowest (solid grey line) and respectively the fastest transitions (dashed grey line).
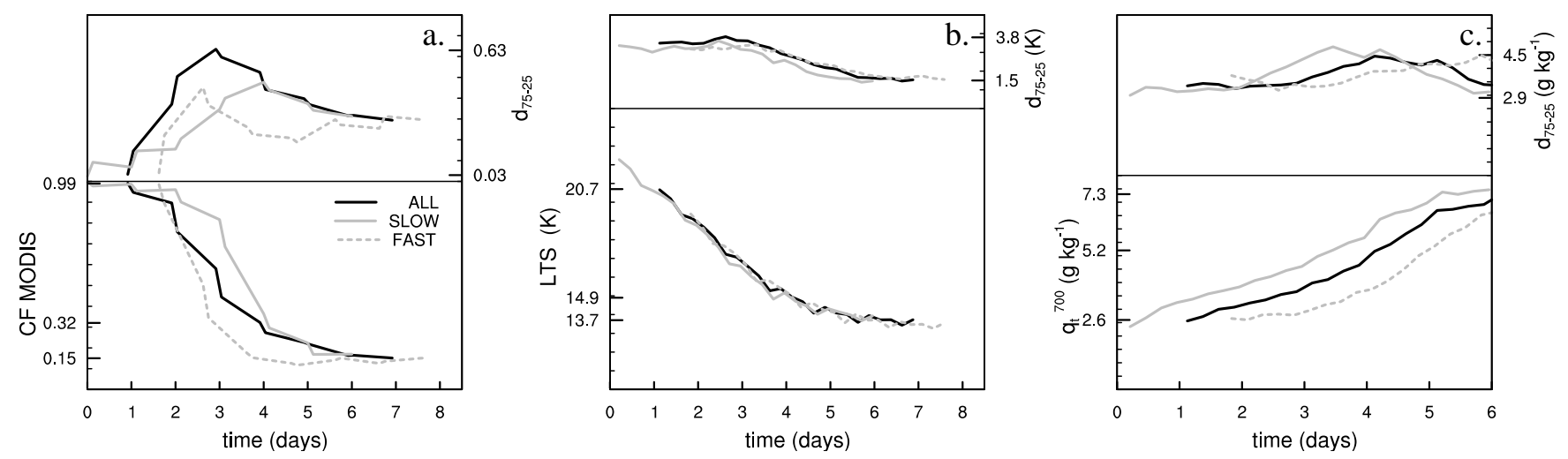

Fig. 6. Same as Figs. 4, $5 \mathrm{~b}$ and e, but with the time axis shifted for the fast and the entire set of trajectories analyzed for NEP, so that they start with the same median LTS as the slow transitions.

these are the months when the transition in cloud fraction is the most likely to occur in the Northern Hemisphere (where the transition trajectories predominantly come from this three month period). In the Southern Hemisphere transition trajectories were more evenly distributed across the original six month period, but for consistency we select the three month period of maximum cloud fraction for both hemispheres.
The composite transition for this three month period is constructed from the corresponding individual trajectories, following the methodology used in Sect. 2.3 for the six month period. To construct a climatological transition for each region, we initialize HYSPLIT with the gridded meteorological ERA-INTERIM fields corresponding to the mean JJA/SON day (over all JJA/SON from 2002 to 2007), and 

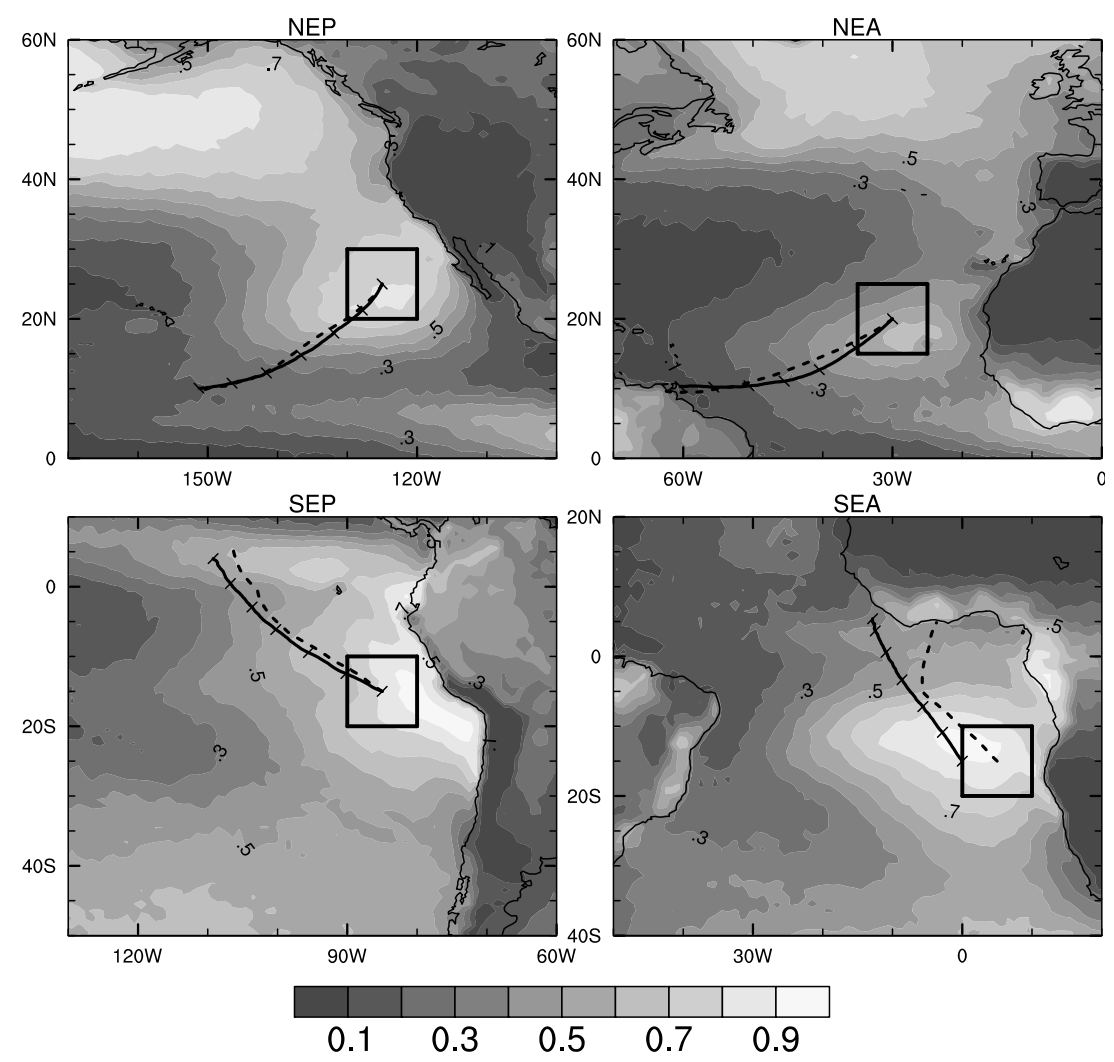

Fig. 7. Average of MODIS Terra (morning) liquid cloud fraction over JJA (NEP, NEA), and respectively SON (SEP, SEA), median of the set of individual trajectories analyzed for these months (full line), and median of the trajectories along the climatological streamlines (dashed line), for the four subtropical oceans.

we compute nine six days trajectories starting in the same points and at the same time as the individual forward trajectories (Sect. 2.1). The mean JJA/SON 2002-2007 fields are then used to derive the properties of these climatological transitions. The median trajectory and the medians of the distributions of the air masses properties over the analyzed set of individual, or climatological, trajectories will be referred to hereafter as the characteristics of the composite (Lagrangian), and respectively, the climatological (Eulerian) transition. The coordinates of the median climatological trajectories are made available in Appendix C.

As expected, given the steadiness of the flow in these regions (Table 1), the climatological trajectory is very close to the composite one for the northern oceans (Fig. 7). More noticeable differences occur in the southern oceans, and more particularly in the SEA, where the flow is less steady and more meridional, so a lower percentage of the trajectories fulfill the primary condition required to be included in the composites, i.e. to go over warmer waters (only 54\% in SEA and $70 \%$ in SEP against $82 \%$ and $88 \%$ in NEA and NEP, respectively).
The climatological transition in cloud fraction has the same character as the composite one in all regions, in the sense that most of the decrease in cloud fraction is observed during the first three days (Fig. 8). To the extent that the initial cloud fraction is somewhat lower, the transition is less abrupt. This is not unexpected since the composite transition includes only the trajectories with a high initial cloud fraction, while the climatological JJA/SON fields used to describe the cloud fraction along the climatological trajectories include all situations. In the SEA, some differences also occur during the last 2 days, when the discrepancies between the climatological and composite trajectories are the most pronounced. Indeed, the climatological trajectory gets more meridional in the vicinity of the equator, so the air parcel following it ends up closer to the coasts, in regions with higher cloud fraction (Fig. 7). The time evolution of the meteorological properties along the two trajectories is also very similar in all four regions (not shown).

Our results confirm that the spatial structure of the climatology in the trades captures the mean temporal evolution of tradewind airmasses during the months of maximum cloudiness in the stratocumulus region, particularly in the NEP. As alluded to above, this result has important implications for both observational and modeling studies of the transitions in 

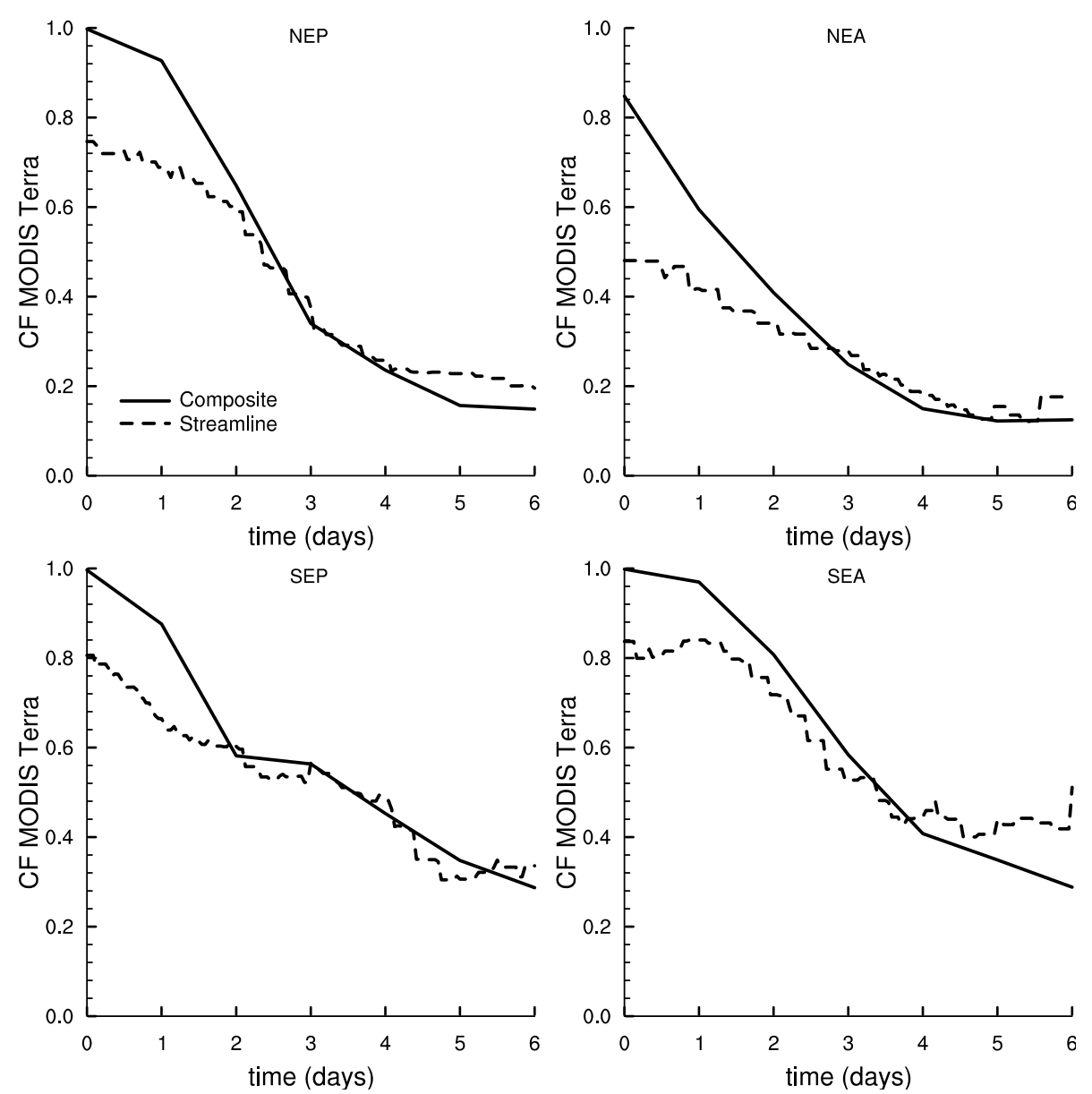

Fig. 8. Median of MODIS Terra liquid cloud fraction distribution: for the set of individual trajectories analyzed for JJA (NEP, NEA), and respectively SON (SEP, SEA) (full line) and for the set of trajectories along the climatological streamlines (dashed line), for the four subtropical oceans.

marine boundary layer cloudiness. Indeed, it implies that satellite observations with a more limited footprint and temporal coverage and which thus insufficiently sample individual trajectories, could, by documenting the structure of the climatological transition, provide usefull information concerning the evolution of the cloud field. Thus, average fields of CALIPSO, CloudSat or MISR products could be for example used to investigate the cloud fraction, the cloud vertical structure, the precipitation and the cloud top evolution along the climatological streamlines. In addition, our analysis suggests that for certain regions and time periods, averaged forcings can be considered as representative of individual trajectories. And can therefore be used to initialize numerical simulations of the transition between the two cloud regimes.

\section{Conclusions}

Satellite data sets and reanalysis of meteorological observations were used to document the transition between marine stratocumulus and shallow cumulus encountered in four subtropical oceans (NEA, NEP, SEA and SEP). The Lagrangian analysis of a large number of air parcel trajectories allowed us to answer, at least to some extent, the questions that motivated our investigation. Based on our analysis we find that:

- the basic character of the transition in cloud fraction has generic features that are evident in four regions where stratocumulus-to-cumulus transitions were analyzed. In all four regions, the cloud fraction decreases sharply during the first three days, while it evolves more gradually during the last three days as the air masses move deeper into the trades.

- the environment in which the transition occurs is also similar across the four regions we consider. In all four 
regions the transition in cloud fraction is associated with strong SSTs increases, an almost commensurate decrease in LTS and gradual humidification of the free troposphere, while the large-scale divergence and the temperature above the boundary layer are roughly constant during the transition period. Marked changes in the large-scale divergence are only observed after the transition in cloud fraction, which suggests that such changes play a relatively minor role in the evolution of the cloud layer. The transition time scale seems to be mostly related to the strength of the LTS (which is governed by the SST) during the first part of the trajectories or prior to their starting time (Klein and Hartmann, 1993; Pincus et al., 1997; Mauger and Norris, 2010), but also (even if to a lesser extent) to the gradual humidification of the free-troposphere.

- the transitions in marine boundary layer cloudiness are a robust feature of the eastern subtropical oceans, during the months with maximum cloudiness in these regions. Their characteristics, depicted by the analysis of individual air parcel trajectories, are thus quite accurately reproduced by climatological (or averaged) data sets, especially for the northern oceans. This result justifies the use of high-resolution sensors (whose spatial coverage requires extensive temporal averaging) to study the climatological transition. Indeed, our analysis emphasizes that in most important respects the climatological transition is representative of individual transitions in cloudiness for periods when the transition is the most likely to happen and regions where the circulation is extremely steady.

Our analysis identifies important environmental factors, or changes, associated with the transition from stratocumulus to cumulus. However, it does not allow us to quantify the relative importance of these factors. And although it seems likely, based on this analysis, that the transition is driven by sharp changes in lower-tropospheric stability as air advects over warmer water, other factors, such as the effects of the humidification of the free troposphere, or the effects of very weak drizzle on boundary layer stratification and dynamics, can not be ruled out. The data analysis performed in this study will therefore be used in the future for initializing/constraining fine scale numerical simulations designed to quantify the relative role of these factors, thereby more clearly establishing the chain of causality in the evolution of the low-level cloud fields of the subtropical oceans.

\section{Appendix A}

\section{Measuring cloud fraction}

The most dramatic aspect of the transition from stratocumulus to shallow cumulus is the rapid reduction in cloud fraction. This quantity is normally determined by using one or more continuous fields (radiances at one or more wavelengths) as inputs to a decision tree; the result is a binary mask in which each pixel is classified as "cloudy" or "clear". Some proportion of pixels may be near whatever thresholds are used to segregate clouds into these categories, so the precise value of cloud fraction can depend strongly on particular algorithmic choices. In this appendix we demonstrate that the precise value of cloud fraction during the transition is ambiguous, but that the behavior of the transition is independent of the algorithms used to determine cloud fraction.

The algorithms used by MODIS to retrieve cloud properties operate in several steps. The first, called the "cloud mask" (Frey et al., 2008; Ackerman et al., 2008) attempts to distinguish those pixels that are likely to contain cloud from those that are entirely clear. This decision is expressed as four confidence levels, and those pixels classified as "cloudy" or "probably cloudy" are further analyzed to determine the cloud thermodynamic phase (ice or liquid) and optical properties (optical thickness and particle size). But in some number of cases it is not possible to identify a combination of phase, particle size, and optical thickness consistent with the observed reflectances at multiple wavelengths. This may occur because the pixel has been mis-classified as cloudy, as is common in regions of sun-glint (Zhao and Girolamo, 2006). In the Collection 5 retrievals used here, pixels adjacent to clear sky are also rejected, as these are subject to retrieval biases.

We determine the boundary-layer cloud fraction using the MODIS "Cloud Fraction Liquid" product which represents the proportion of pixels in each $1^{\circ}$ cell for which retrievals of optical thickness and particle size were successfully performed (and for which the blackbody emission temperature exceeds $273 \mathrm{~K}$ ). We eliminate the possibility of masking by high clouds by excluding cells whose value of "Cloud Fraction Ice" exceeds 5\%. As an alternative, we might have used the proportion of pixels determined "cloudy" or "probably cloudy" by the cloud mask. This value is available as "Cloud Fraction Day" and it is substantially higher than the "Cloud Fraction Liquid" following the trajectories we selected (Fig. A1, panel a). To the extent that cloud fraction could be determined less ambiguously (by using instruments with much higher spatial resolution, for example), the two cloud fraction products are likely to bound this value.

But the behavior of the transition does not depend on the precise value of cloud fraction. Figure A1, panel b, shows the transition determined using the median value of both products along the trajectory, where the cloud fraction has been scaled as $(\mathrm{CF}(t)-\mathrm{CF}(t=6$ : days $)) /(\mathrm{CF}(t=0)-\mathrm{CF}(t=6$ : 

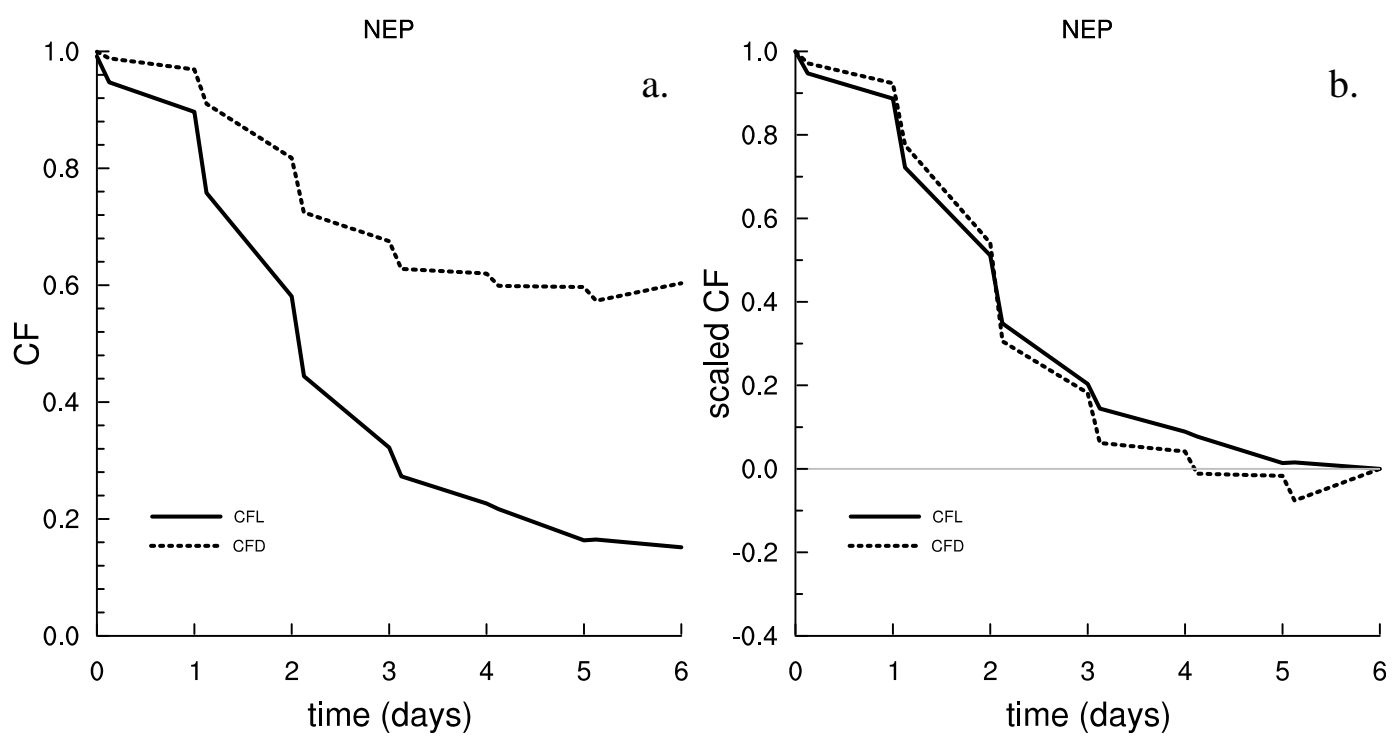

Fig. A1. (a) Time evolution of the median of MODIS "Cloud Fraction Liquid" (CFL, full lines) and "Cloud Fraction Day" (CFD, dashed lines) distributions for the set of trajectories analyzed for the NEP. For both cloud fraction products only the ice-free pixels (i.e. CFI $<5 \%$ ) are used to derive these distributions. (b) Time evolution of the medians of "Cloud Fraction Liquid" and "Cloud Fraction Day" distributions, scaled as $(\mathrm{CF}(t)-\mathrm{CF}(t=6$ : days $)) /(\mathrm{CF}(t=0)-\mathrm{CF}(t=6$ : days $))$.

days)). We show results for the NEP here, but the behavior is identical in all regions, namely that cloud fraction decreases from its maximum value (near 1 in both products) to its minimum (approx. 20\% for "Cloud Fraction Liquid" and 60\% for "Cloud Fraction Day") over the space of three days, with the bulk of the transition occurring in days three and four.

We infer that the transition is not an artifact of how one measures cloud fraction.

\section{Appendix B}

\section{Additional characteristics of the transitions}

In this appendix we include a discussion of other properties of the air masses during their equatorward flow, that are more challenging to measure with satellite-based sensors and are hence more difficult to interpret, but to which our arguments are not overly sensitive.

LWP retrievals are generally subject to different sources of error (Seethala and Horvath, 2009), which lead to considerable discrepancies between the LWPs provided by different sensors. Seethala and Horvath (2009) emphasize for example the systematic differences between the Wentz algorithm used by AMSR-E and the optical LWP retrieval performed by MODIS. Namely, MODIS overestimates AMSR-E LWP in overcast domains, but it noticeably underestimates it in broken scenes (Table 1 in Seethala and Horvath, 2009). Although to some extent microwave retrievals can be considered more trustworthy than the optical retrievals of the LWP, the Wentz (microwave) algorithm has its own sources of error, such as the cloud-rain partitioning (Seethala and Horvath, 2009). This cloud-rain partitioning is performed whenever the cloud total water path retrieved with Wentz algorithm is superior to $180 \mathrm{~g} \mathrm{~m}^{-2}$. The applied rain parameterization is however rather simplistic, being based on a study of NEP extratropical cyclones.

We used both AMSR-E and MODIS datasets to examine the evolution of the LWP along the trajectories. Our analysis corroborates the noticeable differences between the two instruments found by Seethala and Horvath (2009) (not shown). We show here as an example the temporal evolution of the LWP distribution obtained from the AMSR-E data set (Fig. B1a). The transition between the two clouds regimes is less evident in LWP than in cloud fraction, even if the diurnal cycle is more marked (Fig. B1a, lower panel). The variability among trajectories increases when the air parcels penetrate a convective regime (after the third day, Fig. B1a, upper panel). Note however that the caveats of Wentz algorithm should be kept in mind while analyzing these results.

We also examined the cloud top temperature (CTT) from MODIS. However, due to surface contamination, MODIS Level-3 data are considerably overestimating the CTT for all scenes with a cloud fraction inferior to 0.9 (Zuidema et al., 2009), and are hence not suited for examining the evolution of the cloud top height during the transition.

Although it identifies rather well precipitation from medium and deep convection, the GPCP data set is not capturing the much weaker precipitation typical for shallow boundary layer clouds, and hence it does not supply useful 

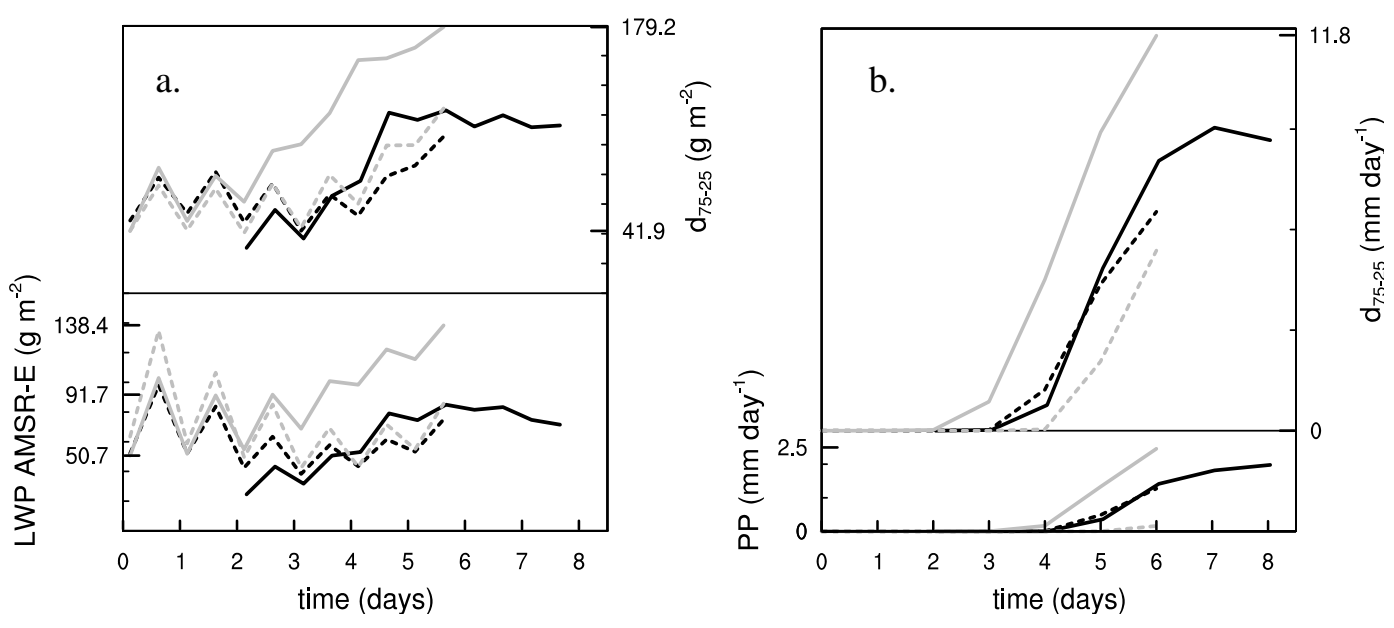

Fig. B1. AMSR-E LWP and GPCP precipitation rate at the surface along the trajectories for the sets of trajectories analyzed in NEA (full black), NEP (full grey), SEA (dashed black) and SEP(dashed grey). Plotting conventions follow those in Fig. 2.

Table C1. The latitude and longitude (degrees) along the climatological trajectories of the four subtropical regions, as described in Sect. 5. The positive/negative signs correspond to the Northern/Southern Hemispheres and to east/west directions, respectively.

\begin{tabular}{ccccc}
\hline & & & & \\
Hours & NEA & SEA & NEP & SEP \\
\hline 0 & $20.00,-30.00$ & $-15.00,5.00$ & $25.00,-125.00$ & $-15.00,-85.00$ \\
6 & $19.05,-31.34$ & $-13.93,3.94$ & $24.00,-125.60$ & $-14.11,-86.34$ \\
12 & $18.16,-32.78$ & $-12.81,2.92$ & $23.08,-126.4$ & $-13.09,-87.68$ \\
18 & $17.37,-34.24$ & $-11.71,1.83$ & $22.29,-127.26$ & $-12.12,-89.17$ \\
24 & $16.62,-35.68$ & $-10.70,0.65$ & $21.44,-128.23$ & $-11.26,-90.71$ \\
30 & $15.87,-37.16$ & $-9.76,-0.48$ & $20.54,-129.31$ & $-10.43,-92.18$ \\
36 & $15.18,-38.70$ & $-8.73,-1.55$ & $19.71,-130.55$ & $-9.45,-93.60$ \\
42 & $14.52,-40.28$ & $-7.69,-2.65$ & $18.98,-131.77$ & $-8.54,-95.06$ \\
48 & $13.92,-41.73$ & $-6.76,-3.77$ & $18.20,-133.05$ & $-7.70,-96.55$ \\
54 & $13.36,-43.15$ & $-5.83,-4.91$ & $17.37,-134.38$ & $-6.84,-97.99$ \\
60 & $12.82,-44.57$ & $-4.81,-5.62$ & $16.57,-135.59$ & $-5.91,-99.11$ \\
66 & $12.29,-46.01$ & $-3.80,-5.73$ & $15.84,-136.58$ & $-5.08,-100.03$ \\
72 & $11.80,-47.41$ & $-2.82,-5.72$ & $15.14,-137.55$ & $-4.29,-100.85$ \\
78 & $11.42,-48.73$ & $-1.82,-5.65$ & $14.44,-138.48$ & $-3.43,-101.55$ \\
84 & $11.02,-50.04$ & $-0.82,-5.45$ & $13.77,-139.42$ & $-2.57,-102.09$ \\
90 & $10.65,-51.40$ & $-0.19,-5.14$ & $13.15,-140.32$ & $-1.82,-102.50$ \\
96 & $10.33,-52.73$ & $1.23,-4.79$ & $12.60,-141.22$ & $-1.07,-102.76$ \\
102 & $10.16,-54.00$ & $2.23,-4.61$ & $12.14,-142.12$ & $-0.18,-103.24$ \\
108 & $9.96,-55.29$ & $3.12,-4.43$ & $11.7,-143.07$ & $0.73,-104.08$ \\
114 & $9.69,-56.58$ & $3.88,-4.15$ & $11.31,-144.02$ & $1.60,-104.82$ \\
120 & $9.52,-57.83$ & $4.42,-3.88$ & $10.99,-145.38$ & $2.54,-105.42$ \\
126 & $9.51,-59.01$ & $4.58,-3.89$ & $10.53,-146.73$ & $3.59,-105.88$ \\
132 & $9.47,-60.21$ & $4.68,-3.90$ & $10.34,-148.04$ & $4.57,-105.17$ \\
138 & $9.45,-61.34$ & $4.69,-3.81$ & $10.27,-149.32$ & $5.36,-106.37$ \\
144 & $9.62,-62.43$ & $4.86,-3.71$ & $9.80,-150.58$ & $5.95,-106.46$ \\
\hline & & & &
\end{tabular}


information concerning the changes in precipitation rate during the bulk of the transition in cloud fraction (the first three days) (Fig. B1b).

The analysis of MODIS aerosol optical depth (AOD) along the trajectories indicated that the AOD varies significantly among the subtropical oceans, with values along the Atlantic trajectories twice as large as along the Pacific ones (not shown). The transition in cloud cover is nonetheless quite similar in the Atlantic and Pacific oceans (Fig. 2a). However the uncertainies in measuring the AOD, especially in overcast regions, and the possibility that aerosol coming from the African coast remains above the boundary layer and does not interact with the cloud layer, make difficult to interpret this as an insensitivity of the transition to aerosol indirect effects.

\section{Appendix C}

\section{Climatological trajectories}

For readers interested in further analyzing these transitions in marine boundary layer cloudiness, we include here (Table $\mathrm{C} 1$ ) the coordinates of the climatological trajectories performed in the four subtropical oceans.

Acknowledgements. ECMWF ERA-INTERIM data used in this study have been obtained from the ECMWF data server (http://www.ecmwf.int/products/data/). AMSRE data are provided by the Remote Sensing Systems (http://remss.com/amsr/amsr_browse.html), and GPCP data have been obtained from the website http://precip.gsfc.nasa.gov/. Roland Draxler is thanked for his help with the HYSPLIT model provided by ARL-NOAA (http://ready.arl.noaa.gov/HYSPLIT.php). We also acknowledge Larry di Girolamo, Steve Ackerman and Steven Platnick for the clarifying discussions concerning the Level-3 MODIS cloud products, as well as Louise Nuijens, Johannes Quaas and three anonymous reviewers for their thoughtful and constructive comments. This work was supported by the Alexander von Humboldt foundation and the Max Planck for Meterorology.

The service charges for this open access publication

have been covered by the Max Planck Society.

Edited by: S. Buehler

\section{References}

Ackerman, S. A., Holz, R. E., Frey, R., Eloranta, E. W., Maddux, B. C., and McGill, M.: Cloud Detection with MODIS. Part II: Validation, J. Atmos. Ocean. Tech., 25, 1073-1086, 2008.

Albrecht, B. A., C.S.Bretherton, D.W.Johnson, W.H.Schubert, and Frisch, A. S.: Atlantic Stratocumulus Transition Experiment ASTEX, B. Am. Meteor. Soc., 76, 889-904, 1995.

Bretherton, C. S.: A conceptual model of the stratocumulus-tradecumulus transition in the subtropical oceans, ICCP proceedings, 374-377, 1992.

Bretherton, C. S. and Pincus, R.: Cloudiness and Marine Boundary Layer Dynamics in the ASTEX Lagrangian Experiments. Part I:
Synoptic setting and vertical structure, J. Atmos. Sci., 52, 27972723, 1995.

Bretherton, C. S. and Wyant, M. C.: Moisture. transport, lowertroposphere stability, and. decoupling of cloud-topped boundary, J. Atmos. Sci., 54, 148-167, 1997.

Bretherton, C. S., Krueger, S. K., Wyant, M. C., Bechtold, P., van Meijgaard, E., Stevens, B., and Teixeira, J.: A GCSS boundary layer model intercomparison study of the first ASTEX Lagrangian experiment, Bound.-Lay. Meteorol., 93, 341-380, 1999.

Seethala, C. and Horvath, A.: Global assessment of AMSR-E and MODIS Cloud Liquid Water Path Retrievals in Warm Oceanic Clouds, J. Geophys. Res., in press, 2010.

De Roode, S. and Duynkerke, P.: Observed Lagrangian transition of stratocumulus into cumulus during ASTEX: Mean state and Turbulence structure, J. Atmos. Sci., 54, 2157-2173, 1997.

Simmons, A. and S. Uppala and D. Dee and S. Kobayashi: ERAINTERIM: New ECMWF reanalysis products from 1989 onwards, ECMWF Newsletter, 110, 25-35, 2006/2007.

Frey, R., Ackerman, S. A., Liu, Y., Strabala, K. I., Zhang, H., Key, J. R., and Wang, X.: Cloud Detection with MODIS. Part I: Improvements in the MODIS Cloud Mask for Collection 5, J. Atmos. Ocean. Tech., 25, 1057-1072, 2008.

King, M., Menzel, W., Kaufman, Y., Tanre, D., Bo-Cai Gao; Platnick, S., Ackerman, S., Remer, L., Pincus, R., and Hubanks, P.: Cloud and aerosol properties, precipitable water, and profiles of temperature and water vapor from MODIS, Geosci. Remote Sens., 41, 442-458, 2003.

Klein, S. A. and Hartmann, D. L.: The Seasonal Cycle of Low Stratiform Clouds, J. Climate, 6, 1587-1606, 1993.

Klein, S. A. and Norris, J. R.: On the Relationships among LowCloud Structure, Sea Surface Temperature, and Atmospheric Circulation in the Summertime Northeast Pacific, J. Climate, 8, 1140-1155, 1995.

Krueger, S. K., McLean, G. T., and Fu, Q.: Numerical Simulation of the Stratus-to-Cumulus Transition in the Subtropical Marine Boundary Layer. Part I: Boundary-Layer Structure, J. Atmos. Sci., 52, 2839-2850, 1995.

Malkus, J. and Riehl, H.: Cloud structure and distributions over the tropical pacific ocean, University of California Press, Berkley and Los Angeles, California, USA, 1964.

Mauger, G. S. and Norris, J.: Meteorological bias in satellite estimates of aerosol-cloud relationships, Geophys. Res. Lett., 34(16), L16824, doi:10.1029/2007GL029952, 2007.

Mauger, G. S. and Norris, J.: Assessing the Impact of Meteorological History on Subtropical Cloud Fraction, J. Climate, in press, 2010.

McDonald, W.: Atlas of climatic charts of the oceans, U.S. Dept. of Agriculture, Weather Bureau, Washington, DC, USA, 1938.

Neiburger, M., Johnson, D., and Chien, C.: Studies of the structure of the atmosphere over the eastern pacific ocean in summer. I. The inversion over the Eastern North Pacific Ocean, University of California Press, Berkley and Los Angeles, California, USA, 1961.

Pincus, R., Baker, M., and Bretherton, C.: What controls stratocumulus radiation properties? Lagrangian observations of cloud evolution, J. Atmos. Sci., 54, 2215-2236, 1997.

Platnick, S., King, M. D., Ackerman, S. A., Menzel, W. P., Baum, B. A., Ridi, J. C., and Frey, R. A.: The MODIS Cloud Products: 
Algorithms and Examples From Terra, IEEE T. Geosci. Remote Sens., 41, 459-473, 2003.

Riehl,H., Yeh, T. C., Malkus, J. J. and La Seur, N. E.: The northeast trade of the Pacific ocean, Quart. Jour. Roy. Meteorol. Soc. , 77, 592-626, 1951.

Schubert, W., Wakefield, J. S., Steiner, E. J., and Cox, S. K.: Marine Stratocumulus Convection. part II: Horizontally Inhomogeneous Solutions, J. Atmos. Sci., 36, 1309-1324, 1979.

Stevens, B.: Cloud-transitions and decoupling in shear-free stratocumulus topped boundary layers, Geophys. Res. Lett., 27, 2557-2560, 2000.

Teixeira, J., Cardoso, S., Bonazzola, M., Cole, J., DelGenio, A., Demott, C., Ffranklin, C., Hannay, C., Jakob, C., Jiao, Y., Karlsson, J., Kitagawa, H., Koehler, M., Kuwano-Yoshida, A., LeDrian, C., Lock, A., Miller, M., Marquet, P., Martins, J., Mechoso, C. R., Meijgaard, E. V., Meinke, I., Miranda, P., Mironov, D., Neggers, R., Pan, H., Randall, D., Rasch, P., Rockel, B., Rossow, W. B., Ritter, B., Siebesma, A., P.Soares, Turk, F., Vaillancourt, P., von Engeln, A., and Zhao, M.: Tropical and sub-tropical cloud transitions in weather and climate prediction models: the GCSS/WGNE Pacific Crosssection Intercomparison (GPCI), J. Climate, submitted, 2009.
Von Ficker, H.: Die Passatinversion, Veroffentl. d. Meteorol. Inst. d. Univ. Berlin, I, Heft 4, 1936.

Wang, S., Albrecht, B. and Minnis, P.: A Regional Simulation of Marine Boundary-Layer Clouds, J. Atmos. Sci., 50, 4022-4043, 1993.

Wyant, M., Bretherton, C., Rand, H., and Stevens, D.: Numerical simulations and a conceptual model of the subtropical marine stratocumulus to trade cumulus, J. Atmos. Sci., 54, 168-192, 1997.

Zhao, G. and Girolamo, L. D.: Cloud fraction errors for trade wind cumuli from EOS-Terra instruments, Geophys. Res. Lett., 33, L20802, doi:10.1029/2006GL027088, 2006.

Zuidema, P., Painemal, D., de Szoeke, S. and Fairall, C.: Stratocumulus Cloud-Top Height Estimates and Their Climatic Implications, J. Climate , 22, 22, 4652-4666, 2009. 